\title{
RELAÇÃO PESSOA E AMBIENTE: ESTUDO DE CASO EM UMA DELEGACIA DE POLÍCIA
}

\author{
BERNARDES, Marina (1); \\ ELY; Vera Helena Moro Bins (2); \\ VERGARA, Lizandra Garcia Lupi (3); \\ (1) Universidade Federal de Santa Catarina, Arquiteta e Urbanista \\ e-mail:arq.marinabernardes@gmail.com \\ (2) Universidade Federal de Santa Catarina, Doutora em Engenharia de Produção \\ e-mail:vera.binsely@gmail.com \\ (3) Universidade Federal de Santa Catarina, Doutora em Engenharia de Produção \\ e-mail: l.vergara@ufsc.br
}

\begin{abstract}
RESUMO
Diante da necessidade de projetar ambientes ou, ainda, adequá-los às necessidades humanas, este artigo apresenta um estudo de caso em uma delegacia de polícia civil, incorporando a Avaliação PósOcupação (APO). A pesquisa está fundamentada na Ergonomia, e foi realizada através de uma abordagem multimétodos, envolvendo visitas, observações e questionários. Objetivou-se compreender o trabalho do agente de polícia e a sua interação com o ambiente físico, visando propor melhorias para o comissariado (local de atendimento ao público). Evidenciou-se que os fatores organizacionais e ambientais têm potencial para prejudicar a atividade de trabalho e o bem-estar dos trabalhadores. Como resultados foram propostas recomendações para qualificar o ambiente, com ênfase nos aspectos arquitetônicos.
\end{abstract}

Palavras chave: ergonomia, avaliação pós-ocupação, delegacia de polícia civil.

\begin{abstract}
Given the need to design environments or adapt them to human needs, this article presents a case study in a civil police station, incorporating the Post-Occupancy Assessment (APO). The research is based on Ergonomics, and was carried out through a multi-method approach, involving visits, observations and questionnaires. The objective was to understand the work of the police officer and his interaction with the physical environment, with the aim of proposing improvements to the police station (place of public service). It has been shown that organizational and environmental factors have the potential to undermine work activity and the well-being of workers. As results, recommendations were proposed to qualify the environment, with emphasis on the architectural aspects.
\end{abstract}

Keywords: ergonomics, post-occupation evaluation, civil police station 


\section{INTRODUÇÃO E JUSTIFICATIVA}

A delegacia de polícia civil é um local de prestação de serviços a toda comunidade, responsável pelo registro e investigação de crimes. É na delegacia que agentes de polícia (AP) realizam boletins de ocorrência, oitivas (entrevistas) de testemunhas e vítimas, além da interrogação de suspeitos. Assim, o trabalho dos AP é fundamental para o bom funcionamento do sistema de justiça brasileiro. Neste contexto, o ambiente pode impactar na qualidade das informações obtidas, ao impossibilitar a privacidade de vítimas e testemunhas, geralmente reflexo da concepção arquitetônica do local ou materiais de revestimento empregados.

Os diferentes impactos que o ambiente pode causar devem ser estudados empiricamente por disciplinas científicas, incorporando além dos preceitos teóricos os aspectos técnicos do ambiente, por exemplo, através da avaliação e modificação do layout e demais elementos do referido espaço (OLIVEIRA E RESENDE, 2017). Visando a melhoria de um ambiente construído (comissariado) e com o objetivo de otimizar o desempenho das atividades realizadas pelos trabalhadores (agentes de polícia), esta pesquisa incorpora a teoria e métodos da Ergonomia do Ambiente Construído que tem como um dos seus preceitos a preocupação a propósito da interferência do ambiente no comportamento humano, a partir de aspectos psicossociais, culturais e organizacionais (VASCONCELOS et al. 2011).

Uma vez interligadas, arquitetura e ergonomia são capazes de potencializar o bem-estar dos usuários e contribuir para a produtividade de trabalhadores (ELY, 2003). Neste sentido, Dawson et al. (2017) evidenciaram, através de experimentos em diferentes espaços físicos, que um maior número de informações é obtido em menor tempo quando realizadas em um ambiente amplo, se comparado a entrevistas realizadas em um ambiente menor. Durante sua atividade de trabalho, entrevistadores e/ou agentes de polícia comumente recebem uma grande quantidade de informações, a qual possui relação direta com o ambiente físico. A entrevista realizada com uma vítima ou testemunha, tem um papel central no desencadeamento de um crime, pois é a partir desta etapa que se inicia a investigação, busca por suspeitos, e o estabelecimento de uma narrativa dos fatos ocorridos (MILNE; SHAW; BULL, 2007). Uma entrevista em que são obtidas poucas informações, por exemplo, impossibilita que os atores de justiça possam realizar o seu trabalho de forma efetiva. Deste modo, ressalta-se a importância de projetar delegacias que levem em conta o aporte científico, visto que é possível potencializar o trabalho realizado.

$\mathrm{Na}$ maioria das delegacias de polícia do Brasil as salas de oitiva e reconhecimento de suspeitos são espaços inexistentes ou improvisados, em que testemunhas de defesa e acusação são mantidas em um mesmo ambiente (STEIN; ÁVILA, 2015). Outro aspecto fundamental a ser considerado é a previsão de uma área de recepção, onde assistentes sociais e/ou psicólogos realizariam a triagem e encaminhariam o cidadão para iniciar o processo de investigação (DE OLIVEIRA, 2004). Todavia, os ambientes de delegacia geralmente são espaços adaptados e não possuem estrutura física compatível com a demanda.

Nos últimos anos, diversas pesquisas têm sido realizadas acerca de procedimentos de entrevistas e coleta de prova testemunhal (BENIA et al. 2015; LOFTUS, 2005). Entretanto, ainda há poucas abordagens feitas por pesquisadores em arquitetura que visam investigar a influência do ambiente. Uma das formas de se investigar a relação entre pessoa e ambiente é através de dados de desempenho físico, níveis de satisfação e percepção dos usuários, que podem ser obtidos por meio da Avaliação Pós-Ocupação (APO). A APO consiste em um conjunto de métodos e técnicas aplicados a pessoa e ambiente visando correlacionar estes dados (EVANS; MCCOY, 1998).

Diante disso, esta pesquisa objetiva avaliar a relação entre o comissariado - ambiente de entrevistas e depoimentos da delegacia e os AP, a fim de produzir recomendações que contribuam para o bem-estar dos usuários, bem como, para a qualidade do serviço prestado. 


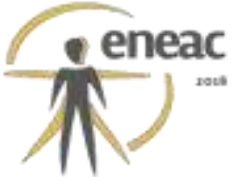

\section{METÓDOS E TÉCNICAS}

A APO nesta pesquisa foi realizada empregando um delineamento o qual foi subdividido em duas etapas de procedimentos: a primeira etapa é composta pela coleta de dados por meio de pesquisa bibliográfica e a segunda por estudo de campo (Figura 01), realizado através de duas análises: a ambiental e dos usuários.

\section{Figura 01 - Sistematização dos métodos aplicados no estudo de campo}

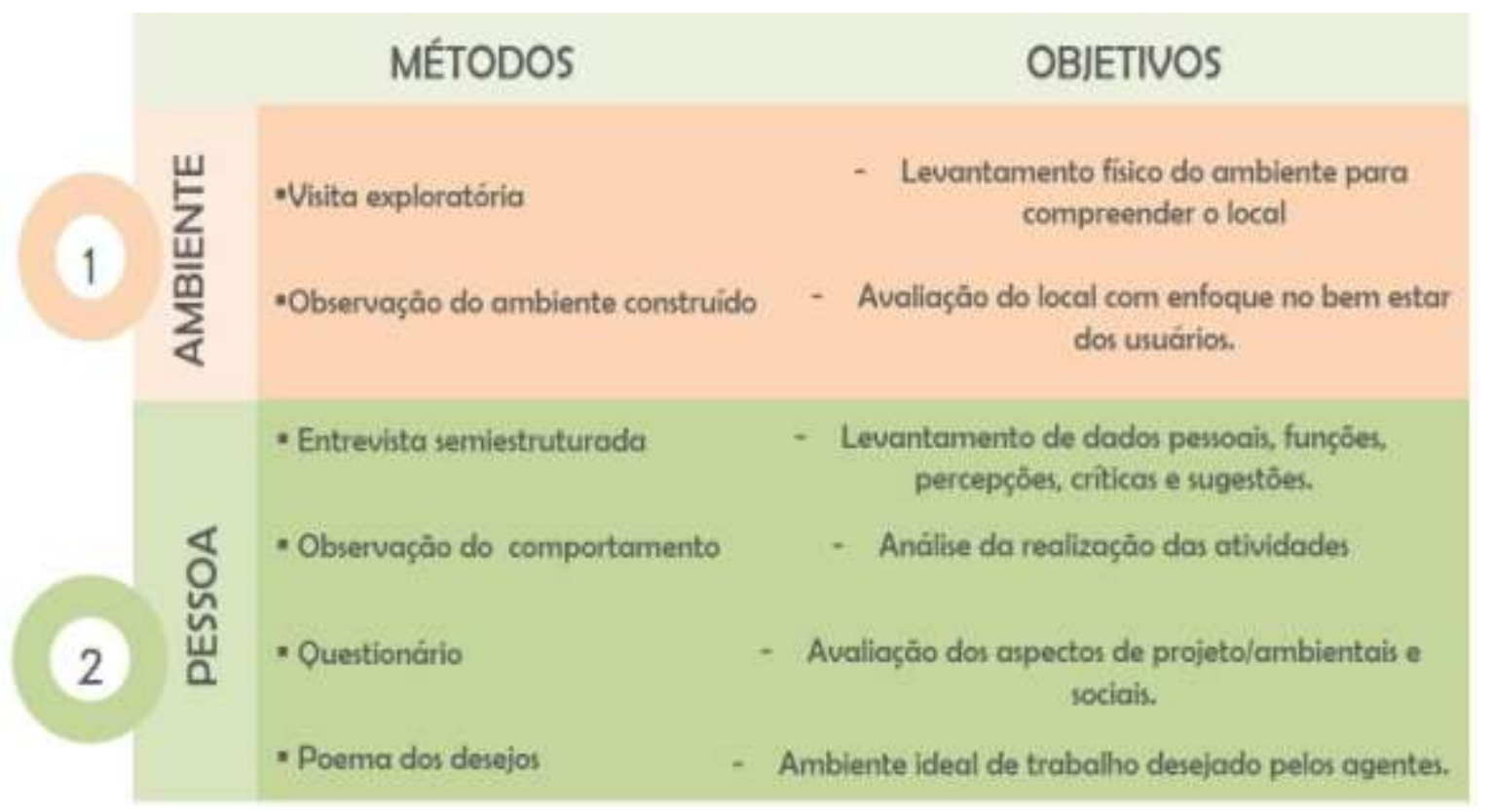

Fonte: Pesquisadoras, 2017.

A visita exploratória, realizada no ambiente estudado, contribuiu para que os pesquisadores pudessem ter um contato com o ambiente, bem como uma percepção própria sobre as atividades realizadas. As informações foram anotadas em uma ficha, elaborada segundo o instrumento proposto por Bertoletti (2011), assim como também foi realizada a observação do comportamento registrada através de um roteiro elaborado conforme Zeisel (1984).

Após a visita, foi possível formular um roteiro de perguntas semiestruturadas em formato de entrevista direcionada à delegada da unidade. As perguntas objetivaram conhecer o funcionamento da delegacia. Para avaliar as percepções dos usuários quanto ao ambiente de trabalho, foi utilizado um questionário composto por quinze perguntas, seguindo a classificação de Baker et al. (1994). Para cada pergunta, os participantes responderam através de uma escala Likert de cinco pontos ( $1=$ péssimo, $5=$ excelente). As perguntas diziam respeito aos seguintes fatores: projetuais, ambientais e sociais. Os fatores de projeto são relativos aos aspectos físicos e funcionais como dimensionamento, layout e estética. Os fatores ambientais são relacionados às condições térmicas, acústicas, lumínicas e, também, olfativas. Os sociais referem-se aos aspectos interpessoais.

Por último, foi utilizada a ferramenta Poema dos Desejos ou Wish Poems (Henry Sanoff, 1995; 2001). Um instrumento eficaz quando se objetiva coletar informações do imaginário das pessoas em relação a um ambiente ideal (SANOFF, 2001). 


\section{(x) $^{\text {reac }}$}

\section{RESULTADOS E DISCUSSÃO}

A Polícia Civil do Estado de Santa Catarina - PCSC é dirigida pelo Delegado Geral de Polícia, e desenvolve os serviços públicos da sua competência, através das Delegacias de Polícia. Santa Catarina possui 459 (quatrocentos e cinquenta e nove) unidades da Polícia Civil, organizadas em 30 Delegacias Regionais de Polícia, e na Capital, através da Diretoria de Polícia da Grande Florianópolis. A Delegacia de Polícia selecionada para esta pesquisa localiza-se em um bairro de Florianópolis-SC, próximo ao centro, e foi implantada de forma adaptada em uma residência existente, onde vem desenvolvendo suas atividades (Figura 02).

Figura 02 - Polícia Civil, delegacia selecionada.

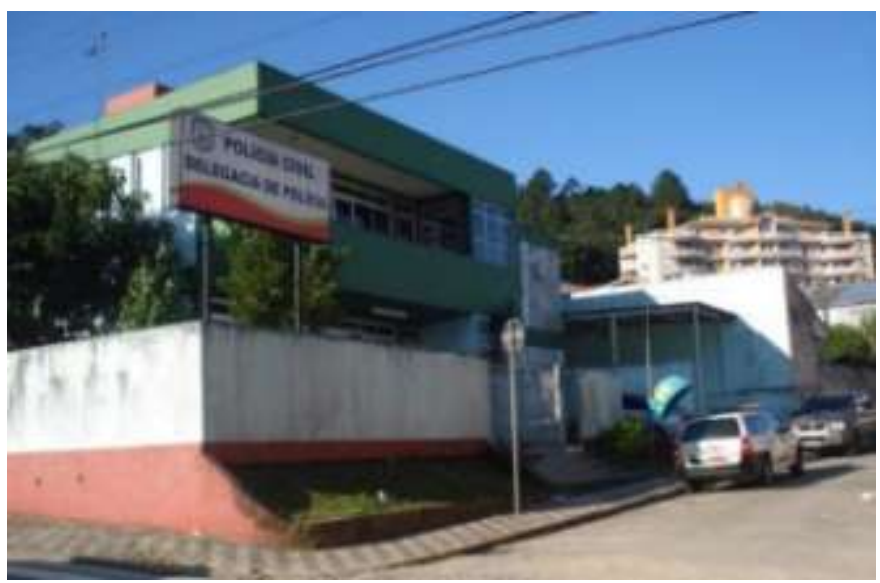

Fonte: Pesquisadoras, 2017.

\section{1 $O$ ambiente}

O ambiente avaliado possui área útil de $15,40 \mathrm{~m}^{2}$, e denomina-se comissariado (Figura 03). O comissariado é a área da delegacia a qual atende todos os clientes e realiza o Boletim de Ocorrência (BO). O local conta com dois ambientes de atendimento e uma sala de espera. Cada ambiente de atendimento possui em média $4,35 \mathrm{~m}^{2}$ onde os agentes realizam os boletins, e são separados por divisórias em PVC.

Figura 03 - Planta baixa atual do comissariado

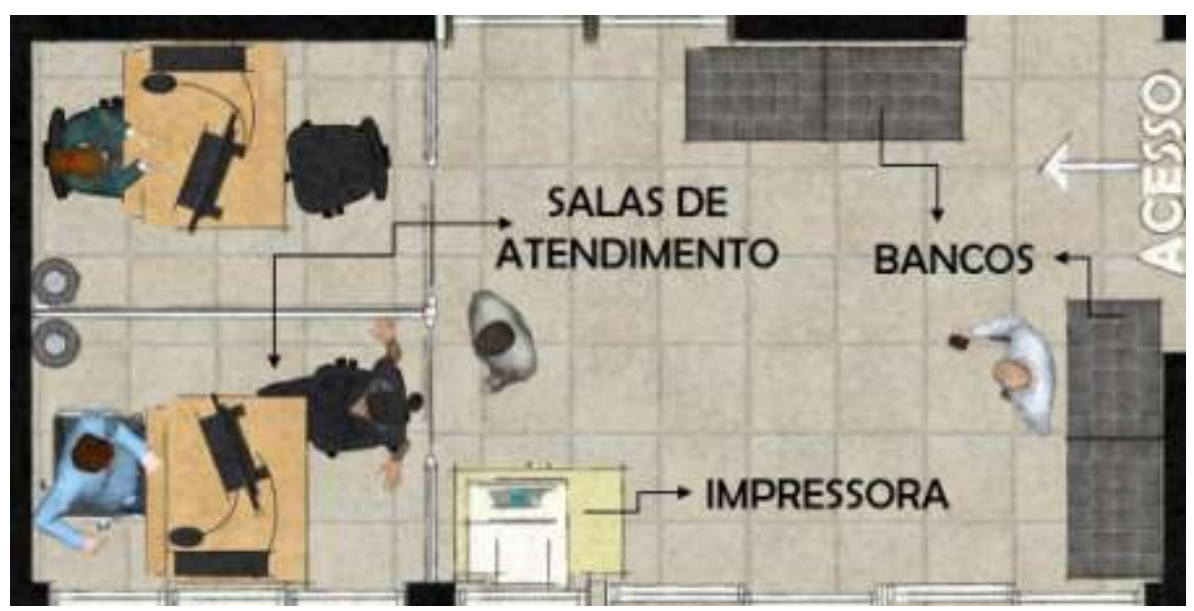

Fonte: Pesquisadoras, 2017. 


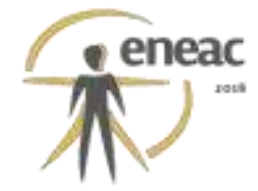

Por meio de observação do ambiente construído e observação do comportamento foi possível identificar alguns aspectos que prejudicam o desempenho da atividade dos AP, assim como os principais conflitos arquitetônicos. Um dos principais empecilhos verificados durante 0 atendimento a clientes, no que se refere ao ambiente físico, é a insuficiência de espaço que ocasiona falta de privacidade para o relato dos depoimentos durante o $\mathrm{BO}$, pois não há como fechar a porta. Para sair da sala os agentes necessitam solicitar que o cidadão (cliente) se levante da cadeira, ou ainda, se retire da sala. Além disso, não há local para guardar arma, colete à prova de balas e algemas - instrumentos necessários para realizar a atividade. Em suma, durante as observações foi possível constatar que as áreas de atendimento são inapropriadas, a impressora está posicionada em um local fora de alcance e exige que o agente deixe a sala para buscar documentos, e também há uma área ociosa na sala de espera.

Figura 03 - Planta baixa do comissariado e seus conflitos

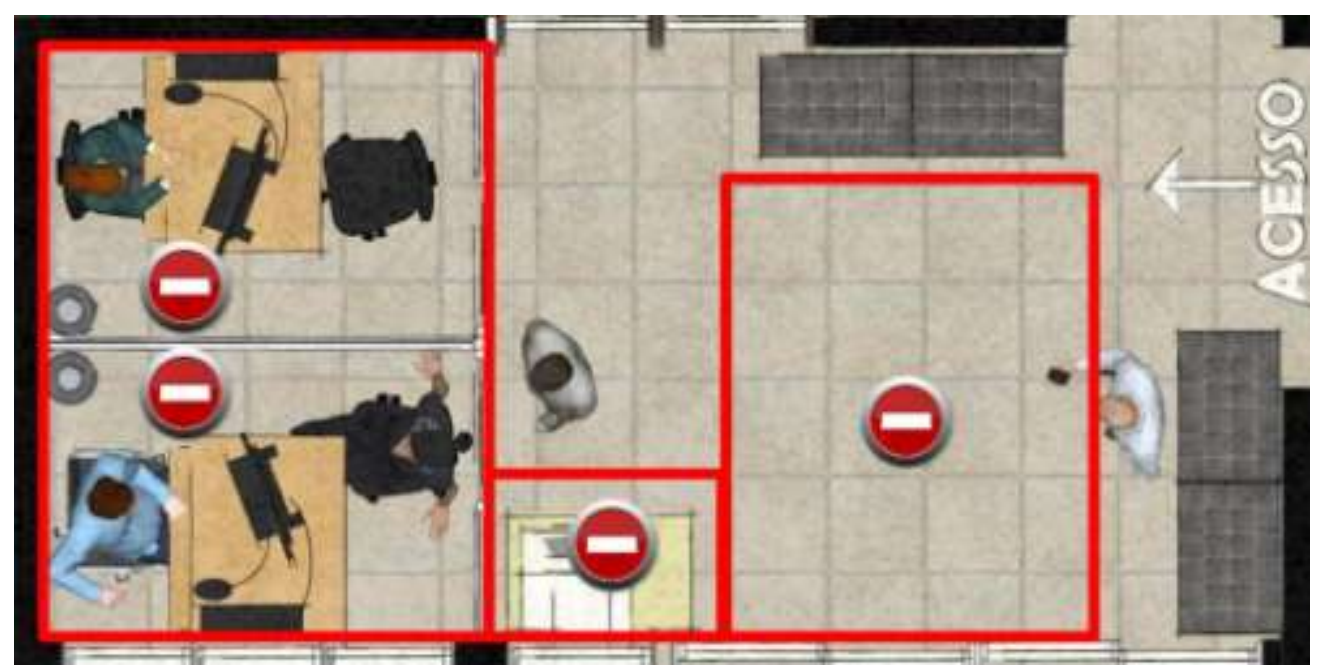

Fonte: Pesquisadoras, 2017.

\subsection{Os usuários}

Para toda unidade de policial civil, é disponibilizada uma equipe composta por delegado de polícia, agente de polícia, escrivão de polícia e, a depender do crime, um psicólogo policial. Neste artigo foram avaliados sete AP, o universo total da Delegacia selecionada, sendo seis homens e uma mulher (tabela 01).

Tabela 01 - Dados coletados sobre os AP

\begin{tabular}{cccccc}
\hline Participante & Idade & Sexo & Estatura $(\mathrm{m})$ & Mão dominante & Pratica atividade física \\
\hline 1 & 34 & Masc. & 1,84 & Destro & Sim \\
\hline 2 & 35 & Fem. & 1,58 & Destro & Não \\
\hline 3 & 38 & Masc. & 1,73 & Canhoto & Sim \\
\hline 4 & 53 & Masc. & 1,71 & Destro & Não \\
\hline 5 & 60 & Masc. & 1,76 & Destro & Sim \\
\hline 6 & 37 & Masc. & 1,71 & Destro & Sim \\
\hline 7 & 50 & Masc. & 1,72 & Destro & Sim
\end{tabular}

Fonte: Pesquisadoras, 2017. 


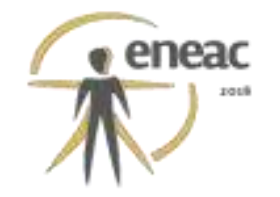

Um dos aspectos a ser observado no que se refere à caracterização dos AP, é a diferença de estatura que varia entre $1,58 \mathrm{~m}$ a $1,84 \mathrm{~m}$, fator que pode comprometer a atividade de trabalho, limitando a movimentação corporal para os agentes mais altos. Esse desconforto evidenciado ao observar a atividade, é uma condição ocasionada pela falta de espaço da sala de atendimento.

\subsubsection{Tarefa prescrita $\times$ Atividade}

Para avaliar a tarefa prescrita, foi acessado o edital de concurso público com denominação do Cargo: Agente de Polícia Civil e grupo: Segurança Pública-Polícia Civil, divulgado no ano de 2017. Através do edital foi possível verificar quais são as funções atribuídas aos AP. Quanto à análise da atividade, através de observações, foi possível avaliar de que forma os AP executam sua função, e as dificuldades enfrentadas. Os AP realizam todos os atendimentos que chegam até a DP e informaram que registram em média 15 a 20 boletins por dia.

No que se refere à diferença entre tarefa e atividade, percebe-se como maior problema a sobrecarga de atendimentos que os AP realizam diariamente. Os AP não apenas realizam o registro de boletim de ocorrência de vítimas e testemunhas, mas também são responsáveis por recepcionar e sanar dúvidas de todas as pessoas que chegam na DP, instruir acerca de como realizar o BO pela internet, e realizar todos os atendimentos por telefone.

Além disso, os AP são responsáveis pela segurança do local, pois como o trabalho é realizado através de plantões $24 / 72$, eles dormem no local, e, mesmo se tratando de um local de risco, não há funcionário contratado como vigilante ou guarda. Os AP entrevistados relataram que a DP já foi alvo de atentados à noite, levando-os a realizar monitoramento por câmeras. Além disto, o comissariado é totalmente exposto por porta-janelas de vidro, fazendo com que muitas vezes os AP optem por trabalhar no escuro para que não sejam visualizados pelo lado externo (Figura 04 e 05).

Figura 04 e 05 - Comissariado

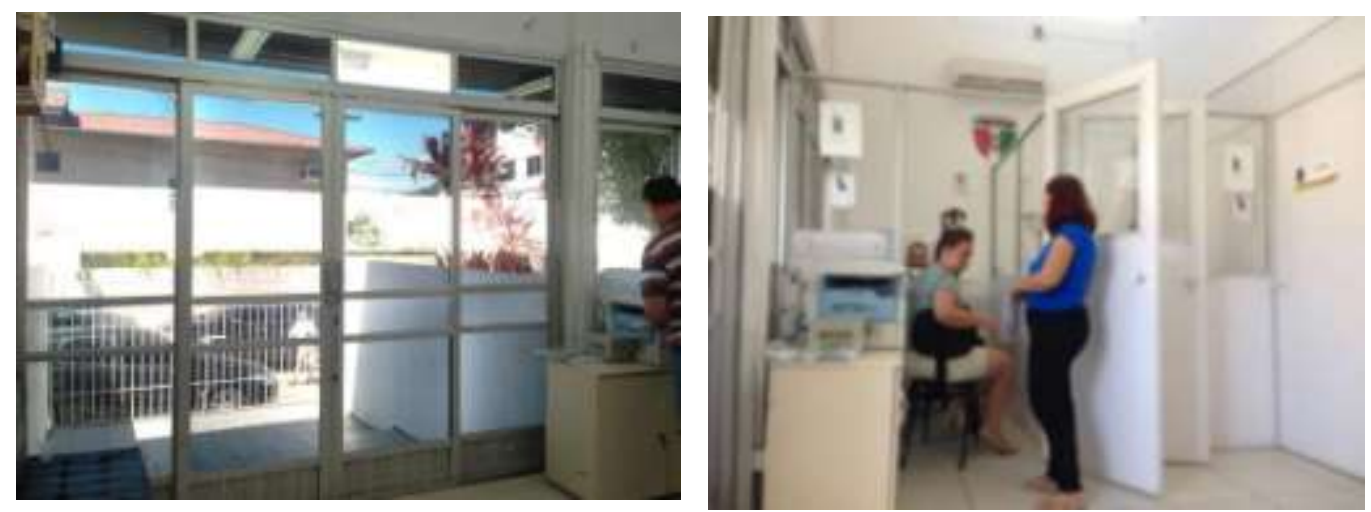

Fonte: Pesquisadoras, 2017.

Outro aspecto verificado é que os AP não conseguem visualizar o rosto das pessoas durante o atendimento, pois a tela do computador bloqueia sua visualização, e o restrito comprimento da mesa impossibilita outro posicionamento para a tela. Desta forma, evidenciou-se através de observações uma adaptação para executar a tarefa de trabalho, condicionada pelo ambiente físico, pois os AP ouvem o relato e depois transcrevem para o computador. Segundo Milne et al. (2007) não é possível obter um relato direto desta forma, pois está além da memória humana ouvir, memorizar e transcrever precisamente um depoimento que muitas vezes pode ser longo e complexo. 


\section{(x) $^{\text {remax }}$}

\subsubsection{Percepção da atmosfera através dos usuários}

Em relação aos resultados obtidos através da aplicação do questionário, quanto aos fatores de projeto, os itens com média mais baixa foram a distribuição do layout, os fluxos e o conforto do mobiliário $(3=$ regular). Os melhores avaliados foram as cores e os revestimentos $(4=$ bom). Na percepção dos AP o ambiente de atendimento deve ser neutro, por isso os tons claros são os mais adequados para o local, do mesmo modo que é a DP.

Quanto aos resultados dos fatores ambientais, o item com média mais baixa avaliado foi o conforto térmico (3), que segundo os AP é ocasionado pela insuficiência do ar condicionado. O melhor avaliado foi o conforto lumínico (4), e relataram que possui boa iluminação artificial e natural em função das aberturas em vidro.

No que se refere aos resultados dos fatores sociais o item com média mais baixa avaliado foi o espaço para descanso (3). Os AP passam 24 horas no turno de trabalho e as pausas ocorrem apenas quando vão para o alojamento, que é um local adaptado e segundo eles, resultou em compartimentos pequenos. O item melhor avaliado, (4) foi o relacionamento entre colegas.

Ao comparar as avaliações dos três fatores - projetuais, ambientais e sociais - aquele que obteve a média mais baixa diz respeito ao projeto arquitetônico. Esse resultado é decorrente da forma como a DP foi implantada: inicialmente uma residência, a qual não sofreu praticamente nenhuma readequação de seus compartimentos, tornando-se um estabelecimento com espaços mal dimensionados.

Os resultados da aplicação do Poema dos Desejos evidenciaram a necessidade de ampliar o espaço, assim como implantar medidas de segurança. Quanto aos elementos mais citados, estes foram subdivididos entre fatores ambientais e organizacionais. As principais características desejáveis pelos AP quanto aos elementos ambientais foram: espaço, segurança, ar condicionado, cadeiras adequadas, local para guardar os instrumentos de trabalho, privacidade para atender os clientes, janelas mais altas e acessibilidade no acesso. Ao que se refere às questões organizacionais foram: implantação de uma triagem ou autoatendimento, central telefônica e/ou secretária eletrônica.

\section{DIAGNÓSTICO E RECOMENDAÇÕES}

Com o auxílio da aplicação de multimétodos empregados neste trabalho, foi possível identificar os principais problemas que interferem na atividade dos AP, tanto organizacionais, como ambientais. Desta forma, desenvolveu-se uma tabela (Tabela 03) síntese contendo recomendações sugeridas pelos pesquisadores.

Tabela 03 - Diagnóstico e recomendações para aspectos organizacionais

\section{Organizacionais}

Problemas identificados

Os AP interrompem o BO para atender o telefone e a porta

Grande demanda de atendimento telefônico

A DP sofre com "trotes" diariamente
Recomendações

Triagem / recepcionista para fazer os encaminhamentos.

Secretária eletrônica ou central telefônica

Bina para identificar os números 
Problemas identificados

Falta de espaço e privacidade no atendimento Mobiliário desconfortável

Fachada de vidro, exposição dos AP

Falta de local para guardar os equipamentos

Impossibilidade de atender 2 pessoas

Ar condicionado insuficiente para o espaço
Recomendações

Ampliação das salas de atendimento Cadeiras adequadas e ampliação das mesas

Fechamento da fachada em alvenaria Inserção de armários no atendimento Inserção de mais cadeiras para atendimento Substituição para um ar condicionado maior

Fonte: Pesquisadoras, 2017.

Na perspectiva das pesquisadoras, mesmo a DP sendo um espaço restrito, através de projeto arquitetônico, ao alterar o layout e reposicionar o mobiliário, pode-se possibilitar uma otimização dos compartimentos, ampliando as salas de atendimento e tornando assim, o ambiente mais funcional e agradável. As alterações relativas ao layout são apresentadas através de uma planta baixa e uma vista (Figura 09, 10 e 11).

As recomendações arquitetônicas propostas são: fechamento das portas/janelas, mantendo apenas janelas altas; reformulação do layout com ampliação da sala 1 e relocação da sala 2 , de modo que possibilite o atendimento de duas pessoas ao mesmo tempo, mantendo-se os vidros entre as salas dos agentes, pois é usado como um elemento de comunicação visual entre eles. Sugere-se ainda: inserção de uma impressora para cada sala; duas mesas de trabalho com dimensão que comporte computador, telefone e cadeiras com alturas reguláveis; implantação de um painel informativo na sala de espera, com o objetivo de informar quais os tipos boletins de ocorrência que se realiza na DP e quais pela internet, assim como, documentos necessários. Sem uma triagem ou recepcionista, acredita-se que com a implantação de um painel informativo o atendimento para sanar dúvidas básicas seria reduzido, e os AP seriam menos interrompidos durante o registro de BO.

Figura 09 - Planta baixa de layout novo proposto

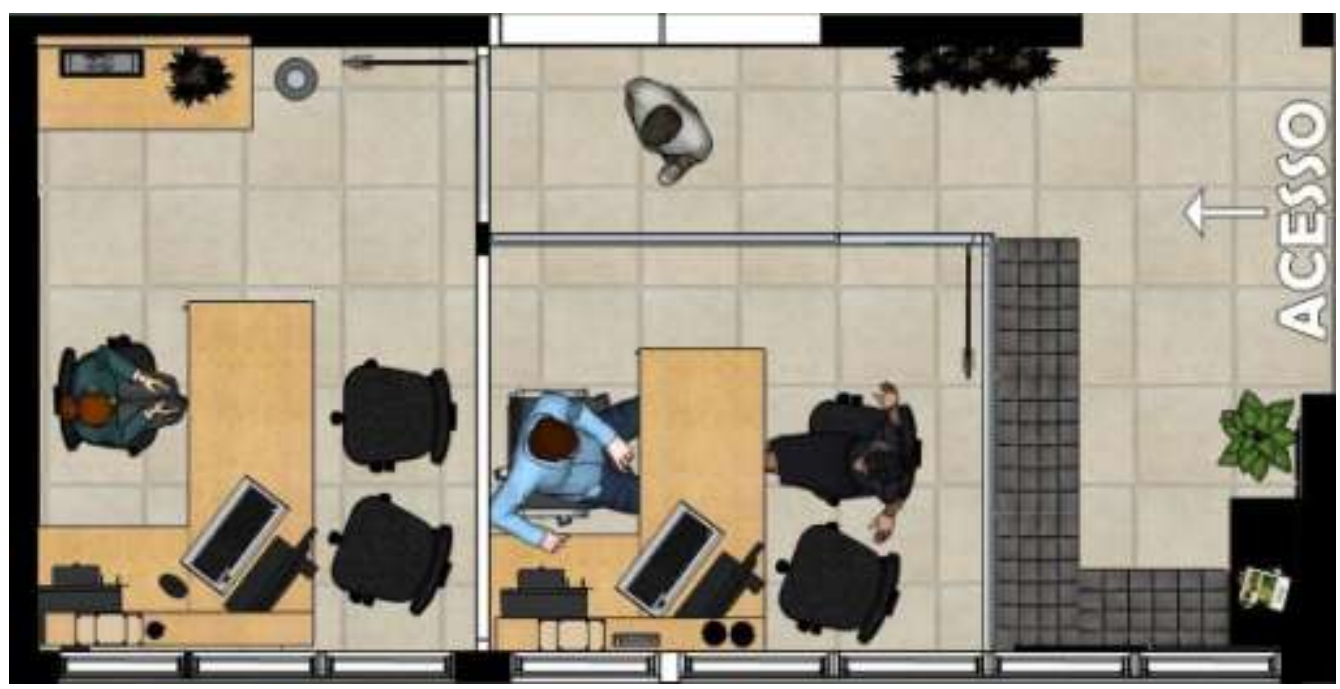

Fonte: Autora, 2017. 


\section{terace \\ Tis \\ N}

Figura 10 - Planta baixa em perspectiva

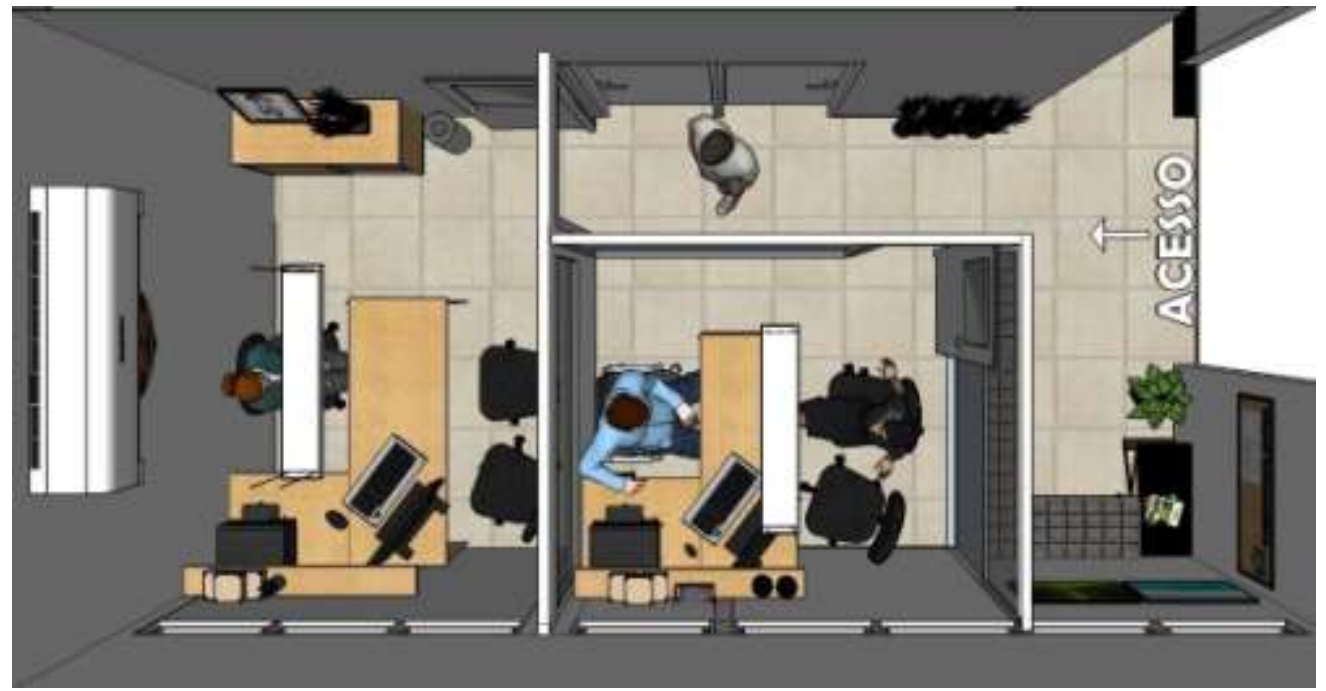

Fonte: Autoras, 2017.

Figura 11 - Vista esquemática

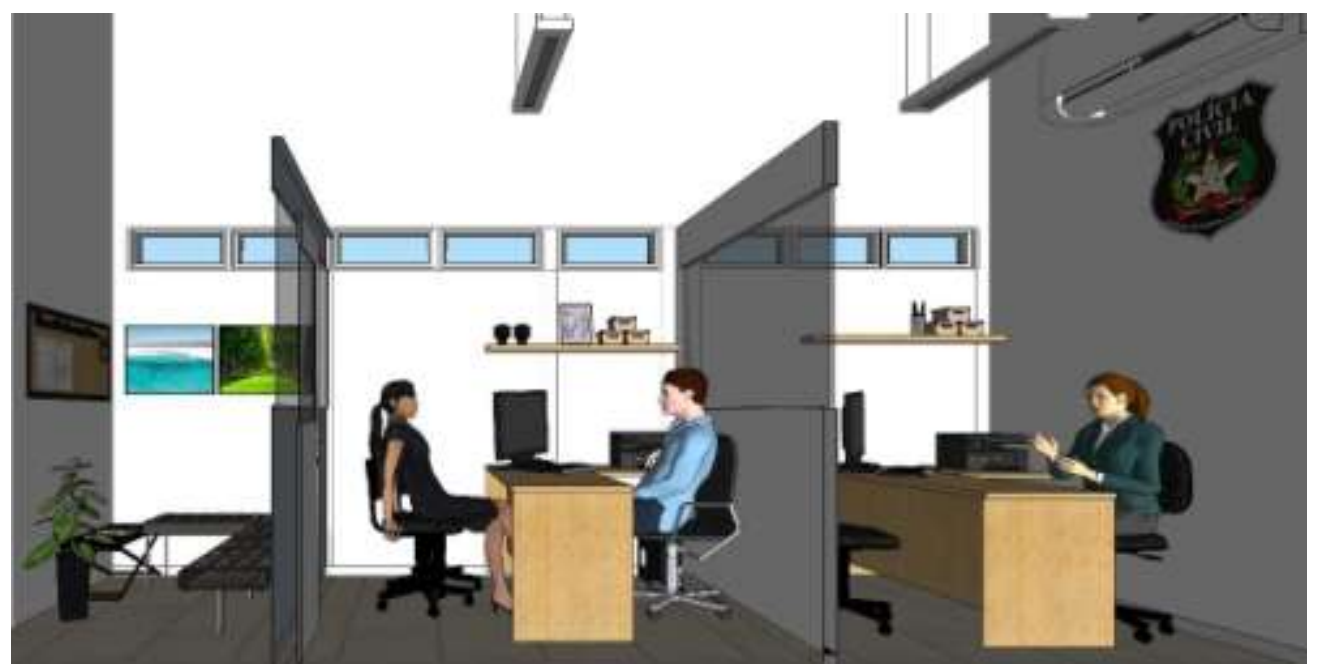

Fonte: Autoras, 2017.

Durante o processo de readequação deste ambiente, teve-se como prioridade otimizar a qualidade do trabalho dos AP e ao mesmo tempo, favorecer a privacidade para o atendimento. Ainda, objetivou-se tornar a DP avaliada mais agradável e convidativa, empregando alguns elementos de humanização na recepção, como quadros, vegetações e revistas. Por fim, um dos principais propósitos foi tornar o ambiente mais seguro, pois este fator foi evidenciado como um dos maiores agravantes do bem-estar dos trabalhadores. Devem ser considerados os desafios desta proposta projetual, pois existe um impasse para a concepção do ambiente ideal de uma delegacia de polícia: por um lado deve ser um ambiente aberto e acolhedor o qual as pessoas sintam-se confortáveis para denunciar crimes ou procurar auxílio, e por outro deve ser um estabelecimento seguro e restrito (MILLIE, 2012). 


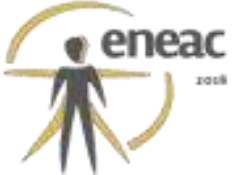

\section{CONSIDERAÇÕES FINAIS}

Um ambiente confortável pode contribuir para a saúde e sensação de bem-estar, como também pode potencializar a capacidade produtiva dos trabalhadores. Neste sentido, é fundamental que a configuração arquitetônica esteja de acordo com as necessidades específicas de cada indivíduo, e dê suporte para que se realize a atividade pretendida.

Constatou-se que com aporte científico da Ergonomia, através da utilização de multimétodos, os instrumentos empregados nesta pesquisa permitiram adquirir uma visão sistêmica sobre o objeto estudado. A pesquisa bibliográfica contribuiu para verificar a importância do ambiente físico no processo de coleta de informações, e as visitas e observações possibilitaram conhecer e compreender tanto o ambiente, quanto o comportamento dos trabalhadores. Com a aplicação do questionário e poema dos desejos, foi possível correlacionar os dados com as observações, verificando com os usuários do espaço quais eram seus anseios e necessidades.

Os resultados deste estudo evidenciaram a interferência do ambiente construído como um fator que pode prejudicar o trabalho do agente de polícia para desempenhar sua tarefa de maneira apropriada. Verificou-se também, privacidade e segurança como elementos essenciais que devem ser considerados no planejamento de um ambiente de entrevista/depoimento, como é o caso do comissariado.

Através desta pesquisa, salienta-se a necessidade de considerar tanto a amplitude da sala como um aspecto fundamental no projeto de delegacias de polícia, quanto às condições ambientais e organizacionais. Verifica-se a necessidade de pesquisas para aprofundar 0 debate deste tema pouco difundido na literatura.

\section{REFERÊNCIAS BIBLIOGRÁFICAS}

BAKER, Julie; GREWAL, Dhruv; PARASURAMAN, Ananthanarayanan. The influence of store environment on quality inferences and store image. Journal of the academy of marketing science, $\mathrm{v}$. 22, n. 4, p. 328-339, 1994.

BENIA, Luis Roberto et al. The NICHD investigative interview protocol: A meta-analytic review. Journal of child sexual abuse, v. 24, n. 3, p. 259-279, 2015.

BERTOLETTI, Roberta. Uma Contribuição da Arquitetura para a Reforma Psiquiátrica: Estudo no Residencial Terapêutico Morada São Pedro em Porto Alegre. Dissertação de Mestrado. Programa de Pós-graduação em Arquitetura e Urbanismo da Universidade Federal de Santa Catarina. Florianópolis, 2011.

BINS ELY, V; Ergonomia + Arquitetura: buscando um melhor desempenho do ambiente físico. In: Anais do $3^{\circ}$ Ergodesign - $3^{\circ}$ Congresso Internacional de Ergonomia e Usabilidade de Interfaces Humano-Tecnologia: Produtos, Programas, Informação, Ambiente Construído. Rio de Janeiro: LEUI/PUC-Rio, 2003.

DAWSON, Evan et al. A room with a view: Setting influences information disclosure in investigative interviews. Law and Human Behavior, v. 41, n. 4, p. 333, 2017.

DE OLIVEIRA, Fernanda Ferreira Metello. A atmosfera do trabalho na era do conhecimento: o caso delegacia legal. Rio de Janeiro: Universidade Federal do Rio de Janeiro - Dissertação de Mestrado em Engenharia de Produção, 2004.

EVANS, Gary W.; MCCOY, Janetta Mitchell. When buildings don't work: the role of architecture in human health. In: Journal of Environmental psychology, v. 18, n. 1, p. 85-94, 1998. 
LOFTUS, Elizabeth F. Planting misinformation in the human mind: A 30-year investigation of the malleability of memory. Learning \& Memory, v. 12, n. 4, p. 361-366, 2005.

MILLIE, Andrew. Police stations, architecture and public reassurance. In: British journal of criminology, v. 52, n. 6, p. 1092-1112, 2012.

MILNE, Becky; SHAW, Gary; BULL, Ray. Investigative interviewing: The role of research. In: Applying psychology to criminal justice, p. 65-80, 2007.

OLIVEIRA, Maria Elisa; RESENDE, Adson E.; RESENDE, Adson E. Análise ergonômica do trabalho na intermediação de diferentes lógicas em projeto: estudo de um laboratório de sedimentologia. In: Revista Ação Ergonômica, v. 12, n. 2, 2017.

SANOFF, Henry. Creating Environments for Young Children. Mansfield, Ohio: BookMasters, 1995. SANOFF, Henry. School Building Assessment Methods. 2001.

STEIN, L. M.; ÁVILA, G. N. Avanços científicos em Psicologia do Testemunho aplicados ao reconhecimento pessoal e aos depoimentos forenses. Secretaria de Assuntos Legislativos, Ministério da Justiça, Brasília 2015.

VASCONCELOS, Christianne Soares Falcão et al. Avaliação Ergonômica do Ambiente Construído: Estudo de caso em uma biblioteca universitária. In: Revista Ação Ergonômica, v. 4, n. 1, 2011.

ZEISEL, John. Inquiry by design: Tools for environment-behaviour research. CUP archive, 1984. 